Bull. Chem. Soc. Ethiop. 2014, 28(2), 215-227.

Printed in Ethiopia

ISSN 1011-3924

DOI: http://dx.doi.org/10.4314/bcse.v28i2.6

(c) 2014 Chemical Society of Ethiopia

\title{
ADSORPTIVE REMOVAL OF FLUORIDE FROM WATER USING NANOSCALE ALUMINIUM OXIDE HYDROXIDE (AIOOH)
}

\author{
Fentahun Adeno, Eyobel Mulugeta, Feleke Zewge ${ }^{*}$ and Yonas Chebude \\ Addis Ababa University, College of Natural Sciences, Department of Chemistry, P.O. Box \\ 1176, Addis Ababa, Ethiopia
}

(Received December 18, 2012; revised March 5, 2014)

\begin{abstract}
In this study the fluoride removal potential of nanoscale aluminium oxide hydroxide (nano$\mathrm{AlOOH})$ has been investigated. The material was produced using aluminium nitrate $\left(\mathrm{Al}\left(\mathrm{NO}_{3}\right)_{3} \cdot 9 \mathrm{H}_{2} \mathrm{O}, 95 \%\right)$, and ammonium bicarbonate $\left(\mathrm{NH}_{4} \mathrm{HCO}_{3}, 98 \%\right)$ and its density and mineralogy were investigated. A series of batch adsorption experiments were carried out to assess parameters that influence the adsorption process. The parameters considered were contact time and adsorbent dose, initial fluoride concentration, and $\mathrm{pH}$. Results showed that most of the adsorption took place during the first $30 \mathrm{~min}$; and equilibrium was reached at one hour contact time with an optimum adsorbent dose of $1.6 \mathrm{~g} \mathrm{~L}^{-1}$ for initial fluoride concentration of $20 \mathrm{mg} \mathrm{L}^{-1}$. The removal efficiency of fluoride increased with increase in adsorbent dosage. The fluoride removal efficiency was increased as the $\mathrm{pH}$ of the solution increases from $\mathrm{pH} 3$ to 8 , but any further increase in $\mathrm{pH}$ led to a decrease in fluoride removal efficiency. Maximum adsorption occurred at around $\mathrm{pH} 7$ with initial fluoride concentration of $20 \mathrm{mg} \mathrm{L}^{-1}$. The adsorption data were well fitted to the Langmuir isotherm model with a maximum adsorption capacity of $62.5 \mathrm{mg} \mathrm{F} \mathrm{g}^{-1}$. The kinetic studies showed that the adsorption of fluoride by nano-AlOOH obeys a pseudo-second order rate equation. The intraparticle diffusion was not a rate-controlling step for the adsorption process. Thus, the overall study indicates that nano- $\mathrm{AlOOH}$ is an efficient defluoridating material.
\end{abstract}

KEY WORDS: Nanoscale AlOOH, Defluoridation, Fluoride removal efficiency, Adsorption capacity, Adsorption kinetics, Adsorption mechanism

\section{INTRODUCTION}

Water can be contaminated by natural or anthropogenic activities such contaminant is fluoride [1]. The source of high fluoride concentrations in ground water is primarily associated with addition of fluoride by volcanic activities, high water-rock interaction, and low calcium concentration. Volcanoes represent the main natural persistent source of fluoride [2]. Fluoride has a narrow range between intakes that cause beneficial and detrimental health effects [3]. At low concentrations, it has beneficial effects on teeth; however excessive exposure to fluoride causes adverse health effects [4]. An intake of more than $6 \mathrm{mg}$ fluoride per day will result in fluorosis [5]. Higher level of fluoride in ground water is a world-wide problem. Ethiopia is one of the countries in the world where a significant percentage of the population suffers from the consumption of fluoride rich drinking water. It has been reported that more than 11 million people in Ethiopian Rift Valley are potentially at risk of fluorosis [6, 7]. The concentrations of fluoride in the Rift Valley communities, which are supplied from boreholes, are reported between 1 and $33 \mathrm{mg} \mathrm{L}^{-1}$ [8]. This high fluoride content in the rift system has been related to volcanoes, high temperature, high subsurface carbon dioxide pressure and low calcium content [9].

Water is the major contributor to the total daily fluoride intake in human body. For this reason, as the concentration of fluoride in drinking water varies, its effect on health also varies accordingly $[10,11]$. WHO recommends a maximum permissible level of $1.5 \mathrm{mg} \mathrm{L}^{-1}$ [11]. The prevention of fluorosis through a range of alternatives is a difficult task, which requires favorable socio-economical conditions of knowledge, motivation, discipline and technique.

*Corresponding author. E-mail: fbeshah@yahoo.com 
Therefore, for poor communities in developing countries like the Rift Valley regions of Ethiopia, where provision of alternative water supply is difficult, treatment might be the most prioritized option to provide safe drinking water.

Currently available treatment methods for removal of excess fluoride from water are broadly divided into three categories based on fluoride removal mechanism: precipitation, adsorption and membrane based methods. Precipitation methods involve the addition of soluble chemicals to the water and fluoride is removed either by precipitation, co-precipitation, or adsorption on to the formed precipitate. It requires much larger dose of chemicals, it has low removal efficiency and has problems associated with large sludge disposal [12]. The use of alum and lime has been extensively studied for defluoridation of drinking water, and it is popularly known as the Nalgonda technique. However, it requires much larger dose of alum, it has low removal efficiency and has problems associated with large sludge disposal $[12,13]$. Membrane methods include reverse osmosis [14], nano-filtration [15], electrodialysis [16] and electro-coagulation [17]. It requires high capital investment cost and high energy consumption, and is not economical as in the case of the Rift Valley regions of Ethiopia.

Thus, adsorption is widely recognized as an ideal and appropriate technique compared to other techniques because of its simplicity and the availability of a wide range of adsorbents, for defluoridation. Recently a wide range of materials have been tested and studied for defluoridation, such as activated alumina [18], activated carbon and cement paste [19], aluminium hydroxide, boehmite [20], bone char [19, 21], various types of clays and red mud, etc. Studies in Ethiopia as well as other developing countries indicated the possibility of using low cost adsorbents like bone char, clay, lateritic soils and other materials [19, 22-24]. However, use of these low cost methods is limited either due to their low efficiency or lack of public acceptance. Therefore, it is of paramount importance to identify materials with high removal capacity, economically, socially and technically feasible options for applications in rural communities.

Recently, aluminium oxide hydroxide has shown superior adsorption capacity, i.e. $23.7 \mathrm{mg}$ $\mathrm{g}^{-1}$ on laboratory scale as compared to activated alumina (1.8-1.9 $\left.\mathrm{mg} \mathrm{F}^{-1}\right)$ [20, 25]. In the last decades, nanotechnologies have developed quickly in various fields and nanometric materials have attracted much attention for their special properties, and there has been growing interest in the application of nanoparticles as sorbents for fluoride removal. Sundaram [26] studied the fluoride removal efficiency of nanoscale hydroxyapatite and showed promising results. The removal of fluoride using nano-alumina had been reported earlier [27] and few reports also showed the potential of nanometer-scale aluminium oxide hydroxide (nano- $\mathrm{AlOOH}$ ) to remove fluoride from aqueous solutions are available [28].

The aim of this study was to assess the defluoridation potential of nanoscale aluminium oxide hydroxide (AlOOH). Effect of contact time, adsorbent dose, initial fluoride concentration, and $\mathrm{pH}$ were investigated. Adsorption isotherms and kinetics of fluoride on nano- $\mathrm{AlOOH}$ were also examined.

\section{EXPERIMENTAL}

\section{Adsorbent}

Aluminium nitrate $\left(\mathrm{Al}\left(\mathrm{NO}_{3}\right)_{3} \cdot 9 \mathrm{H}_{2} \mathrm{O}, 95 \%\right)$ (Merck, Germany) and ammonium bicarbonate $\left(\mathrm{NH}_{4} \mathrm{HCO}_{3}, 98 \%\right)$ (Merck, Germany) were used as starting materials. Aluminium nitrate and ammonium bicarbonate solutions, which were prepared by dissolving the salts in deionized water, were added from two separate burettes to deionized water retained in a reaction vessel dropwise to precipitate aluminium cations as transparent gel in the form of hydroxides. The mixture was stirred and maintained at $70{ }^{\circ} \mathrm{C}$ and then, the $\mathrm{pH}$ of the precipitate was controlled in 
the range of 7.5 to 8.5 using $\mathrm{HNO}_{3}$ and/or $\mathrm{NaOH}$ (Merck, Germany). This $\mathrm{pH}$ range was chosen based on the literature value [27].

The following chemical reactions could occur during preparation:

$$
\begin{aligned}
& \mathrm{NH}_{4} \mathrm{HCO}_{3}+\mathrm{H}_{2} \mathrm{O} \rightarrow \mathrm{NH}_{4} \mathrm{OH}+\mathrm{H}_{2} \mathrm{O}+\mathrm{CO}_{2} \uparrow \\
& \mathrm{Al}\left(\mathrm{NO}_{3}\right)_{3}+3 \mathrm{NH}_{4} \mathrm{OH} \rightarrow \mathrm{Al}(\mathrm{OH})_{3}+3 \mathrm{NH}_{4} \mathrm{NO}_{3} \\
& \mathrm{Al}(\mathrm{OH})_{3} \rightarrow \mathrm{AlOOH} \downarrow+\mathrm{H}_{2} \mathrm{O}
\end{aligned}
$$

The precipitate were finally filtered, washed thoroughly with deionized water and subsequently with ethanol followed by acetone to avoid contamination of sodium ions. The collected precipitate was dried at room temperature and ground to fine powder using mortar and pestle.

\section{Reagents and stock solutions}

All the chemicals and reagents used in this study were of analytical grade. A $1000 \mathrm{mg} \mathrm{F} \mathrm{L}^{-1}$ fluoride stock solution was prepared by dissolving $2.21 \mathrm{~g}$ of anhydrous sodium fluoride $(99.0 \%$ $\mathrm{NaF}$, BDH Chemicals Ltd Poole, England) in $1000 \mathrm{~mL}$ deionized water. All the synthetic fluoride solutions for adsorption and analysis were prepared by diluting an appropriate aliquot of the stock solution in deionized water. Total ionic strength adjustment buffer (TISAB) solution was prepared by following a recommended procedure [29], except that CDTA (trans1,2-diamineciclohexane-tetracetic acid) was replaced by EDTA.

Analysis of fluoride

A pH/ISE meter (Orion Model, EA 940 Expandable Ion Analyzer, USA) equipped with combination fluoride selective electrode (Orion Model 96-09, USA) was employed for the measurement of fluoride ion concentration. The fluoride concentration was measured according to the procedure described in the instrument s manual. The method of direct potentiometry was used, where the concentration was read directly. The fluoride ion selective electrode was calibrated prior to each experiment. All measurements were made at room temperature $(22 \pm 2$ $\left.{ }^{\circ} \mathrm{C}\right)$.

\section{Characterization of adsorbent}

The determination of absolute density was carried out by the MicroMeritics AccuPyc 1330, Pycnometer, USA. The solid samples (ca $100 \mathrm{mg}$ ) were digested in a microwave digester with $3: 1$ ratio of $30 \% \mathrm{HCl}$ and $65 \% \mathrm{HNO}_{3}$ for about $1 \mathrm{~h}$ and $20 \mathrm{~min}$. Then the solution was diluted in 1:100 ratio by deionized water and the elemental composition ( $\mathrm{Li}, \mathrm{B}, \mathrm{Na}, \mathrm{Mg}, \mathrm{Al}, \mathrm{Si}, \mathrm{P}, \mathrm{Cl}, \mathrm{K}$, $\mathrm{Ca}, \mathrm{V}, \mathrm{Cr}, \mathrm{Mn}, \mathrm{Fe}, \mathrm{Co}, \mathrm{Ni}, \mathrm{Cu}, \mathrm{Zn}, \mathrm{As}, \mathrm{Se}, \mathrm{Sr}, \mathrm{Mo}, \mathrm{Cd}, \mathrm{Sn}, \mathrm{Sb}, \mathrm{Ba}, \mathrm{La}, \mathrm{W}, \mathrm{Au}, \mathrm{Hg}, \mathrm{Ti}, \mathrm{Pb}, \mathrm{Th}$, $\mathrm{U}, \mathrm{Br}, \mathrm{Bi}, \mathrm{Cs}, \mathrm{Nb}$ ) was determined by ICP-OES (SPECTRO CIROSCCD, Germany), ICP-MS (Agilent 7500CX, USA), and sulfate was determined by ion chromatography (Metrohm 761, Switzerland). The X-ray diffraction (XRD) pattern of nano-AlOOH was recorded on an X-ray diffractometer (X'pert PRO, PANalytica, The Netherlands) using $\mathrm{Cu} \mathrm{K} \alpha$ radiation $(\lambda=0.1542$ $\mathrm{nm}$ ) with a $0.05^{\circ} / \mathrm{min}$ step scanned from 5 to $80^{\circ}$ in $2 \theta$ angle. Thermogravimetric analysis (TGA) was carried out using Mettler Toledo AG-TGA/SDTA851e, Switzerland.

\section{Batch adsorption}

All the batch experiments were conducted in $500 \mathrm{~mL}$ Erlenmeyer flask containing $500 \mathrm{~mL}$ of fluoride spiked deionized water at room temperature $\left(22 \pm 2{ }^{\circ} \mathrm{C}\right)$ to evaluate fluoride removal 
efficiency and capacity of the adsorbent under continuous mixing condition with magnetic stirrer. A sample solution was periodically taken out of the flask and filtered through a $0.2 \mu \mathrm{m}$ filter paper (ADVATEC) for fluoride analysis. Then, residual fluoride concentration was measured immediately after equal volume of TISAB was added to $5 \mathrm{~mL}$ sample solution. All the experiments were performed in triplicate and the mean values were used.

The amount of fluoride adsorbed per unit mass of the adsorbent at any time $\mathrm{t}\left(q_{t}, \mathrm{mg} \mathrm{g}^{-1}\right)$, and the adsorption efficiency ( $\% \mathrm{R}$, determined as the fluoride removal percentage relative to the initial concentration) of the system, was calculated as:

$\mathrm{q}_{\mathrm{t}}=\left[\left(\mathrm{C}_{\mathrm{o}}-\mathrm{C}_{\mathrm{t}}\right) / \mathrm{m}\right] \times \mathrm{V}$

$\% \mathrm{R}=\left[\left(\mathrm{C}_{\mathrm{o}}-\mathrm{C}_{\mathrm{t}}\right) / \mathrm{C}_{\mathrm{o}}\right] \times 100$

where, $\mathrm{C}_{\mathrm{o}}$ and $\mathrm{C}_{\mathrm{t}}$ are the fluoride concentrations in solution $\left(\mathrm{mg} \mathrm{L}^{-1}\right)$ initially and at any time $(\mathrm{t})$, respectively, $\mathrm{m}$ the mass of the adsorbent $(\mathrm{g})$ and $\mathrm{V}$ is the volume (L) of the solution. In Eq. (1), when $C_{t}=C_{e}$ (fluoride concentrations remaining in the solution at equilibrium in $\mathrm{mg} \mathrm{L}^{-1}$ ), $\mathrm{q}_{\mathrm{t}}=$ $\mathrm{q}_{\mathrm{e}}$ (equilibrium adsorption capacity in $\mathrm{mg} \mathrm{g}^{-1}$ ).

The effect of dose of the adsorbent, initial fluoride concentration, contact time and raw water $\mathrm{pH}$ were investigated by varying any one of the parameters and keeping the other parameters constant. The effect of adsorbent dose and contact time were studied by varying the dosage in the range of 0.4 to $2.0 \mathrm{~g} \mathrm{~L}^{-1}$ at constant initial fluoride concentration of $20 \mathrm{mg} \mathrm{L}^{-1}$. The effect of initial fluoride concentration and contact time were investigated by varying fluoride concentrations from 5-30 mg L $\mathrm{m}^{-1}$ at constant adsorbent dose of $1.6 \mathrm{~g} \mathrm{~L}^{-1}$. The effect of raw water $\mathrm{pH}$ on the adsorption of fluoride on to the adsorbent was studied by varying the solution $\mathrm{pH}$ from 3-10. The $\mathrm{pH}$ was adjusted to the desired level either with $0.1 \mathrm{M} \mathrm{NaOH}$ or $0.1 \mathrm{M} \mathrm{HNO}_{3}$. The $\mathrm{pH}$ was measured with $\mathrm{pH} / \mathrm{ion}$ meter (WTW Inolab pH/ION Level 2, Germany) using unfilled $\mathrm{pH}$ glass electrode. The meter was calibrated each time measurements were being performed by using $\mathrm{pH}$ calibration buffers.

Isotherm experiments were conducted by mixing constant fluoride concentration of $50 \mathrm{mg}$ $\mathrm{L}^{-1}$ with 9 series of different dosages varying from $1.0-20.0 \mathrm{~g} \mathrm{~L}^{-1}$. The liquid-adsorbent mixture was agitated for $24 \mathrm{~h}$ to ensure equilibrium. The kinetic analysis of the adsorption data is based on reaction kinetics of pseudo-first order and pseudo-second order mechanisms. Adsorption kinetics was determined using constant surface loading of $25 \mathrm{mg} \mathrm{g}^{-1}\left(1.6,0.8\right.$ and $0.4 \mathrm{~g} \mathrm{~L}^{-1}$ adsorbents for the corresponding fluoride concentration of 40,20 and $10 \mathrm{mg} \mathrm{L}^{-1}$, respectively). The change in $\mathrm{pH}$ during adsorption of $\mathrm{F}$ on nano- $\mathrm{AlOOH}$ was determined by equilibrating constant adsorbent dose of $1.6 \mathrm{~g} \mathrm{~L}^{-1}$ of fluoride sample solution whose $\mathrm{pH}$ varied from 3-10 at constant initial $\mathrm{F}$ concentration of $20 \mathrm{mg} \mathrm{L}^{-1}$. The $\mathrm{pH}$ was adjusted with $0.1 \mathrm{M} \mathrm{HNO}_{3}$ or $0.1 \mathrm{M}$ $\mathrm{NaOH}$. The $\mathrm{pH}$ was measured after $1 \mathrm{~h}$, and the $\mathrm{pH}$ change was evaluated to describe the adsorption mechanism.

\section{RESULTS AND DISCUSSION}

\section{Characterization of adsorbent}

The absolute density of nano-AlOOH was found to be $2.18 \mathrm{~g} \mathrm{~cm}^{-3}$, and is smaller than the density of boehmite, $3.01 \mathrm{~g} \mathrm{~cm}^{-3}$ [30]. Based on the result, it can be concluded that the lower density of nano-AlOOH indicates the material might have more pore spaces, and make nano$\mathrm{AlOOH}$ an effective defluoridating agent.

The elemental composition analysis of the adsorbent showed the presence of $\mathrm{AlOOH}$ (97.6\%), $\mathrm{Na}_{2} \mathrm{O}(1.2 \%), \mathrm{SiO}_{2}(0.37 \%), \mathrm{Fe}_{2} \mathrm{O}_{3}(0.31 \%), \mathrm{CaO}(0.14 \%)$ and the rest constituted by 
compounds of $\mathrm{K}, \mathrm{Mg}, \mathrm{Sr}, \mathrm{Zn}$ and $\mathrm{Cu}$. The presence of high amount of $\mathrm{Na}$ might be from the $\mathrm{NaOH}$ solution used for adjusting the $\mathrm{pH}$ during synthesis of nano-AlOOH.

The X-ray diffraction (XRD) pattern (Figure 1) of nano-AlOOH shows a broad peak in the reflection angle range for two theta values between (10-15, 25-30, 35-40, 45-50 and 60-70), which indicates high crystalline order of the synthesized compound. This is consistent and in agreement with XRD results of nanosized $\mathrm{AlOOH}$ synthesized by other researches [27, 28]. In addition to that, the XRD pattern showed broadening of the peaks, indicative of the ultra fine nature of the crystallite. The crystallite size calculated using Scherrer's formula (Eq. 3) is about $3.67 \mathrm{~nm}[31]$.

$\mathrm{L}=\mathrm{K} \lambda / \beta \operatorname{Cos} \theta$

where, L is the crystallite size, $\mathrm{K}$ is the Scherrer constant $(0.94$, for FWHM of spherical crystalliets), $\lambda$ is the XRD radiation wavelength in $\mathrm{nm}(\lambda=0.1542 \mathrm{~nm}), \beta$ is Full Width at Half Maximum (FWHM) in radians, and $2 \theta$ is the diffraction angle.

As can be seen from Figure 2, the dehydration of the aluminium oxide-hydroxide appears to occur in three steps with a total weight loss of approximately $31.0 \%$. The first two endothermic peaks at $100-300{ }^{\circ} \mathrm{C}$ that resulted in $19.8 \%$ weight loss could be attributed to the removal of physically adsorbed water, and the third step at $340-500{ }^{\circ} \mathrm{C}$ which resulted in $11.2 \%$ weight loss could be due to the conversion of $\mathrm{AlOOH}$ into $\mathrm{Al}_{2} \mathrm{O}_{3}$.

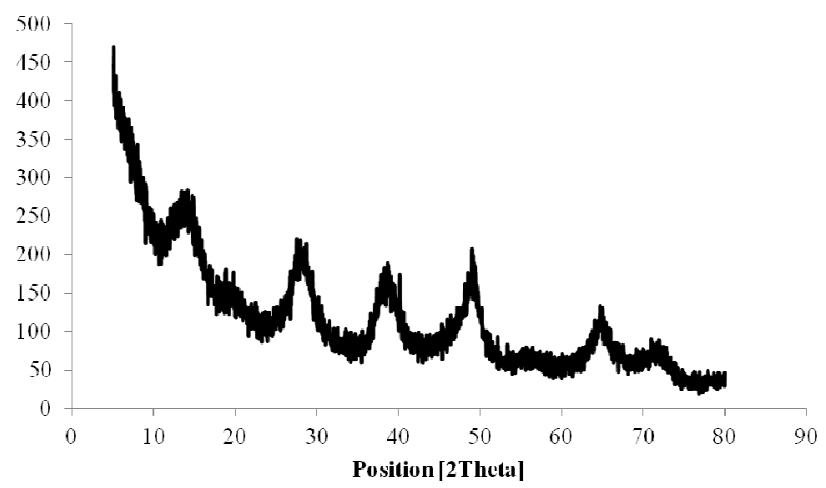

Figure 1. The X-ray diffraction pattern of nano-AlOOH.

Effect of adsorbent dose and contact time

It is observed that the removal of fluoride ions increases with an increase in the amount of adsorbent (Figure not shown). For all these runs, initial fluoride ion concentration was fixed at $20 \mathrm{mg} \mathrm{L}^{-1}$. The amount of adsorbent dose was varied between 0.4 and $2.0 \mathrm{~g} \mathrm{~L}^{-1}$ in aqueous solution at their optimal $\mathrm{pH}$ values.

The result shows that the reaction was very fast during the initial $30 \mathrm{~min}$, and a contact time of about $60 \mathrm{~min}$ is enough to remove $95 \%$ of the fluoride in solution with an adsorbent dose greater than or equal to $1.6 \mathrm{~g} \mathrm{~L}^{-1}$ at room temperature $(22 \pm 2){ }^{\circ} \mathrm{C}$. This indicates that longer contact time did not have much effect. 


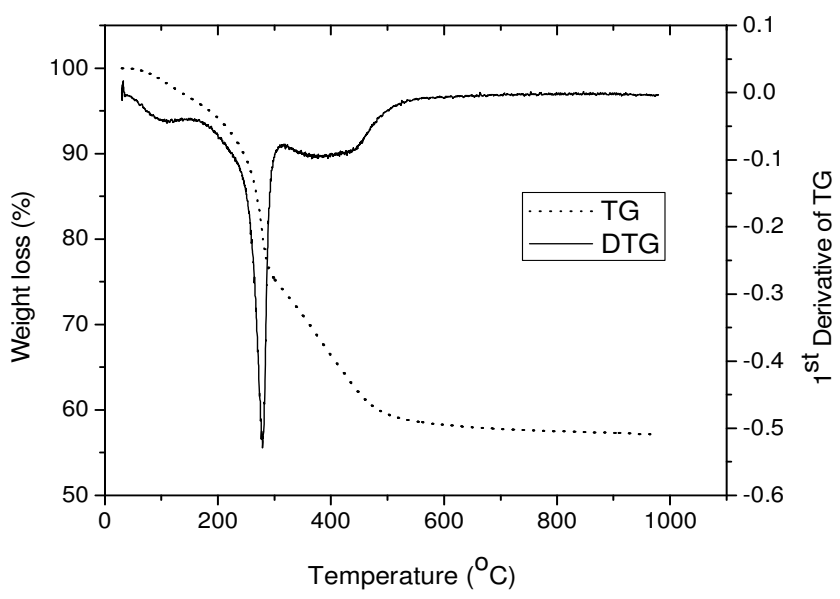

Figure 2. Thermogravimetric curve, TG (dotted line), and derivative of thermogravimetic curve, DTG (solid line) of nano-AlOOH.

The fluoride removal efficiency (\%) was significantly increased with dose as reflected by the measured residual fluoride concentration (Figure 3). The percentage removal of fluoride increases significantly up to an adsorbent dose of $1.6 \mathrm{~g} \mathrm{~L}^{-1}$, however no significant change was observed beyond this dose under the experimental conditions used. The increase in fluoride removal efficiency was due to the large number of available $F$ binding sites resulting from the increased in adsorbent dosage. Thus, $1.6 \mathrm{~g} \mathrm{~L}^{-1}$ of adsorbent dose was taken as an optimum dose for further experiments.

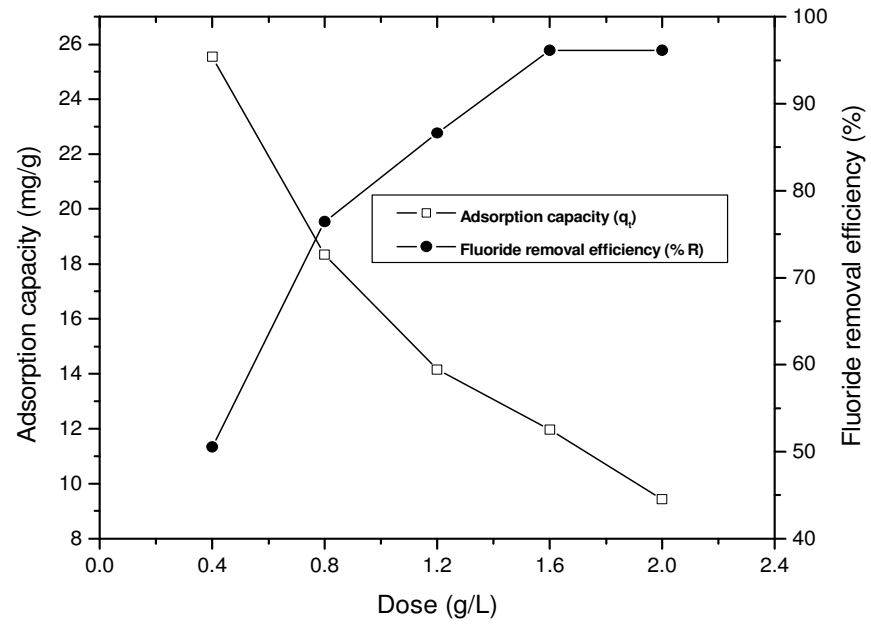

Figure 3. Adsorption capacity $\left(\mathrm{q}_{\mathrm{t}}, \mathrm{mg} / \mathrm{g}\right)$ and fluoride removal efficiency $(\% \mathrm{R})$ as a function of adsorbent dose $\left(\mathrm{C}_{\mathrm{o}}=20 \mathrm{mg} \mathrm{L}^{-1}\right.$, contact time $\left.=60 \mathrm{~min}\right)$.

Conversely, the adsorption capacity decreases with increasing dose (Figure 3), this possibly due to constant initial $\mathrm{F}^{-}$concentration. To maintain reasonable capacity and high removal 
efficiency, the surface loading (i.e., the mass ratio of fluoride to adsorbent dose) should be lower than the optimum value (i.e., the surface loading for optimum fluoride removal, about $90 \%$, obtained from Figure 3 is $13.25 \mathrm{mg} \mathrm{g}^{-1}$ or less). A dose of $1.6 \mathrm{~g} \mathrm{~L}^{-1}$ corresponding to the capacity of about $11.88 \mathrm{mg} \mathrm{F} \mathrm{g}^{-1}$ of adsorbent was considered for further adsorption experiments, which is greater than the reported surface loading of micronized $\mathrm{AlOOH}(11.25$ $\mathrm{mg} \mathrm{F} \mathrm{g}^{-1}$ of adsorbent) for the corresponding dose of $1.6 \mathrm{~g} \mathrm{~L}^{-1}$ [20].

\section{Effect of initial fluoride concentration and contact time}

The fluoride removal efficiency of the adsorbent increases with decreasing initial fluoride concentration at the initial stage of adsorption (data not shown). It can be observed that the adsorption of fluoride from water is relatively more rapid at lower initial concentrations. This is due to the utilization of more accessible energetically active site on the adsorbent surface. Thus, the initial fluoride concentration had an influence on the equilibrium sorption time, and significant fluoride removal efficiency $(>90 \%)$ was observed when the initial fluoride was less than or equal to $20 \mathrm{mg} \mathrm{L}^{-1}$ for a contact time of $60 \mathrm{~min}$. However, adsorption of more concentrated fluoride solution approached equilibrium slowly.

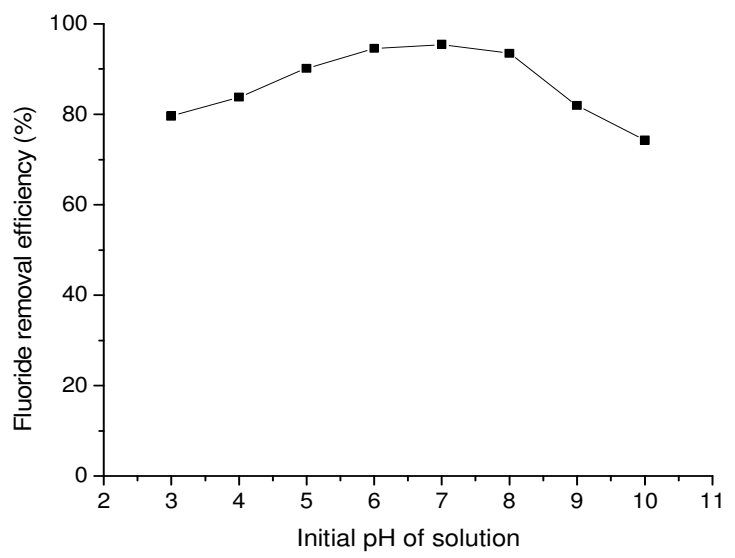

Figure 4. Effect of initial solution $\mathrm{pH}$ on fluoride removal efficiency of the media (dose $=1.6 \mathrm{~g}$ $\mathrm{L}^{-1}, \mathrm{C}_{\mathrm{o}}=20 \mathrm{mg} \mathrm{L}^{-1}$, and contact time $=60 \mathrm{~min}$ ).

Effect of raw water $\mathrm{pH}$

Figure 4 shows the influence of initial solution (raw water) $\mathrm{pH}$ on the fluoride removal efficiency of the adsorbent. It is evident that percentage of fluoride removal increases as the $\mathrm{pH}$ of the solution increases within a $\mathrm{pH}$ range of 3-8 and reach a maximum at $\mathrm{pH}=7$. Further increase of the solution $\mathrm{pH}$ from 8-10 decreases the removal efficiency and it becomes significant after $\mathrm{pH}$ of 9 . This is consistent with the work of [27] and [28]. The fluoride uptake capacity of this media is more favored within the $\mathrm{pH}$ range of 5 to 8 , possibly due to the development of positive sites at the surface of the adsorbent. The decrease in the fluoride removal below $\mathrm{pH} 5$ is possibly due to the protonation of the fluoride ion. On the other hand, at a $\mathrm{pH}$ above 8, fluoride removal efficiency decreases possibly due to the development of negative charge on the adsorbent surface and/or stronger competition from hydroxide ions, since both $\mathrm{OH}^{-}$and $\mathrm{F}$ have the same charge and ionic radii [19] and [20]. This is consistent with the study of Wang [28]; nano-AlOOH has a $\mathrm{pH}_{\mathrm{pzc}}$ of 7.8, which means that the surface of the 
adsorbent presents a net positive charge when $\mathrm{pH} \leq 7.8$. Therefore, the high fluoride removal efficiency in $\mathrm{pH}$ less than 8 can be attributed to the gradual increase in electrostatic forces of attraction between positively charged surface and fluoride ion, and low efficiency in alkaline medium can be explained by the repulsion between the negatively charged surface and fluoride.

\section{Adsorption isotherm}

The experimental data of equilibrium isotherm for fluoride adsorption were modeled using the most frequently used isotherms, such as Freundlich, Langmuir, Dubinin-Radushkevich (D-R) and Temkin isotherm. Freundlich isotherm model assumes unlimited sorption sites which correlate better with heterogeneous surface of the adsorbent media [29]. The Langmuir isotherm model assumes uniform surface having equivalent adsorption sites with no lateral interactions between the adsorbed species. Thus, Langmuir refers to homogenous sorption, where each molecule has equal sorption activation energy with no transmigration of the adsorbate in the plane of the surface. Dubinin-Radushkevich (D-R) model used to describe the mechanism of adsorption process, estimate both of the maximum adsorption capacity and the apparent energy of adsorption to distinguish whether the adsorption type is chemical or physical in nature.

The Temkin isotherm model was chosen to evaluate the adsorption potentials of the adsorbent for adsorbate. The model considers the effects of indirect adsorbate/adsorbent interactions on adsorption isotherms. It assumes that the heat of adsorption of all the molecules in the layer would decrease linearly with coverage due to adsorbate/adsorbent interactions and the adsorption is characterized by a uniform distribution of binding energies, up to some maximum binding energy [32].

The linear plot of $\mathrm{C}_{\mathrm{e}} / \mathrm{q}_{\mathrm{e}}$ versus $\mathrm{C}_{\mathrm{e}}$ (Figure 5) indicates the applicability of Langmuir adsorption isotherm. The correlation coefficient obtained from Langmuir isotherm was the highest compared to the values obtained from Freundlich, D-R and Temkin isotherms (Table 1). Therefore, the Langmuir isotherm is the best-fit isotherm for the adsorption of fluoride on to this adsorbent under the experimental conditions used in this study.

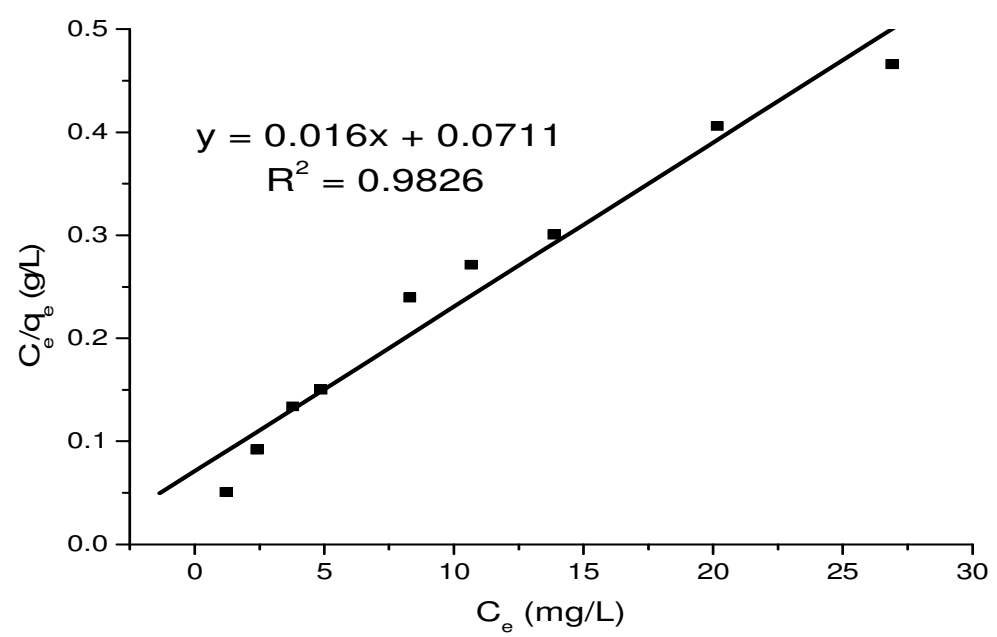

Figure 5. Linearized Langmuir isotherm of the adsorption process $\left(\mathrm{C}_{\mathrm{o}}=50 \mathrm{mg} \mathrm{L}^{-1}\right.$, contact time $=24 \mathrm{~h}$, and $\mathrm{pH}=7$ ). 
Table 1. Langmuir, Freundlich, Dubinin-Radushkevich (D-R), and Temkin model constants at $\mathrm{pH}=7$ and $25^{\circ} \mathrm{C}$.

\begin{tabular}{|c|c|c|c|}
\hline Isotherm models & \multicolumn{2}{|c|}{ Constants } & Correlation coefficients $\left(\mathrm{R}^{2}\right)$ \\
\hline \multirow{3}{*}{$\begin{array}{l}\text { Langmuir } \\
\frac{C_{e}}{q_{e}}=\frac{1}{q_{m} b}+\frac{C_{e}}{q_{m}}\end{array}$} & $\mathrm{q}_{\mathrm{m}}$ & & \multirow{3}{*}{0.9826} \\
\hline & $\left(\mathrm{mg} \mathrm{g}^{-1}\right)$ & $\left(\mathrm{L} \mathrm{mg}^{-1}\right)$ & \\
\hline & 62.5 & 0.225 & \\
\hline \multirow{2}{*}{$\begin{array}{l}\text { Freundlich } \\
\log q_{e}=\log K_{f}+1 / n \log C_{e}\end{array}$} & $\begin{array}{c}\mathrm{K}_{\mathrm{F}} \\
\left(\mathrm{mg} \mathrm{g}^{-1}\right)\end{array}$ & $\begin{array}{c}1 / \mathrm{n} \\
\left(\mathrm{L} \mathrm{mg}^{-1}\right)\end{array}$ & \multirow[b]{2}{*}{0.9778} \\
\hline & 20.75 & 0.286 & \\
\hline \multirow{2}{*}{$\begin{array}{l}\text { Dubinin-Radushkevich (D-R) } \\
\ln q_{e}=\ln q_{s}-\beta \varepsilon^{2} \\
\varepsilon=R T \ln \left(1+\frac{1}{C_{e}}\right) \\
E=(-2 \beta)^{-1 / 2}\end{array}$} & $\begin{array}{c}\mathrm{q}_{\mathrm{s}} \\
\left(\mathrm{mg} \mathrm{g}^{-1}\right)\end{array}$ & $\begin{array}{c}\mathrm{E} \\
\left(\mathrm{kJ} \mathrm{mol}^{-1}\right)\end{array}$ & \multirow[b]{2}{*}{0.9754} \\
\hline & 112.8 & 13.15 & \\
\hline \multirow{2}{*}{$\begin{array}{l}\text { Temkin } \\
q_{e}=\frac{R T}{b_{T}} \ln K_{T}+\frac{R T}{b_{T}} \ln C_{e}\end{array}$} & $\begin{array}{l}\mathrm{K}_{\mathrm{T}} \times 10^{3} \\
\left(\mathrm{~L} \mathrm{mg}^{-1}\right)\end{array}$ & $\mathrm{RT} / \mathrm{b}_{\mathrm{T}} \times 10^{-3}$ & \multirow[b]{2}{*}{0.9614} \\
\hline & 92.75 & 0.56 & \\
\hline
\end{tabular}

\section{Adsorption kinetics}

The kinetic analysis of the adsorption data is based on reaction kinetics of pseudo-first orders (results were not shown) and pseudo-second order mechanisms. The experimental data were well fitted to pseudo-second order rate equation by using the Lagergren's rate equation as shown below [33] and [34]:

$\mathrm{dq}_{\mathrm{t}} / \mathrm{d}_{\mathrm{t}}=\mathrm{K}_{2}\left(\mathrm{q}_{\mathrm{e}}-\mathrm{q}_{\mathrm{t}}\right)^{2}$

$\mathrm{d}\left(\mathrm{q}_{\mathrm{e}}-\mathrm{q}_{\mathrm{t}}\right) /\left(\mathrm{q}_{\mathrm{e}}-\mathrm{q}_{\mathrm{t}}\right)^{2}=-\mathrm{K}_{2} \mathrm{dt}$

For the boundary conditions $\mathrm{t}=0$ to $\mathrm{t}=\mathrm{t}$ and $\mathrm{q}_{\mathrm{t}}=0$ to $\mathrm{q}_{\mathrm{t}}=\mathrm{q}_{\mathrm{t}}$, the integrated form of Eq. (5) becomes:

$$
1 /\left(\mathrm{q}_{\mathrm{e}}-\mathrm{q}_{\mathrm{t}}\right)=1 / \mathrm{q}_{\mathrm{e}}+\mathrm{K}_{2} \mathrm{t}
$$

Thus, this is the integrated rate law for a pseudo-second order reaction, Eq. (6) and can be rearranged to obtain Eq. (7), which has a linear form:

$\mathrm{t} / \mathrm{q}_{\mathrm{t}}=1 / \mathrm{K}_{2} \mathrm{q}_{\mathrm{e}}^{2}+\mathrm{t} / \mathrm{q}_{\mathrm{e}}$

where, $\mathrm{q}_{\mathrm{e}}$ and $\mathrm{q}_{\mathrm{t}}$ are the amount of adsorbed fluoride at equilibrium and at any time $\mathrm{t}\left(\mathrm{mg} \mathrm{g}^{-1}\right)$, respectively. $k_{2}\left(\mathrm{~g} \mathrm{mg}^{-1} \mathrm{~min}^{-1}\right)$ is equilibrium rate constant of second order sorption and $\mathrm{t}$ is the contact time (min). The rate constant $k_{2}$, can be determined by plotting $\mathrm{t} / \mathrm{q}_{\mathrm{t}} \mathrm{vs}$. $\mathrm{t}$ based on equation (7). Figure 6 shows the average pseudo-second order plot of fluoride adsorption kinetics on the adsorbent each with the same initial load. Thus, the three rate constants of an adsorbent averaged to get a single rate constant $\left(2.22 \mathrm{~g} \mathrm{~min}^{-1} \mathrm{mg}^{-1}\right)\left(\mathrm{x}^{-3} 0^{-3}\right)$, and the correlation coefficient was found to be near to unity. Therefore, the pseudo-second order model is suitable to describe the adsorption kinetics of nano-AlOOH. 


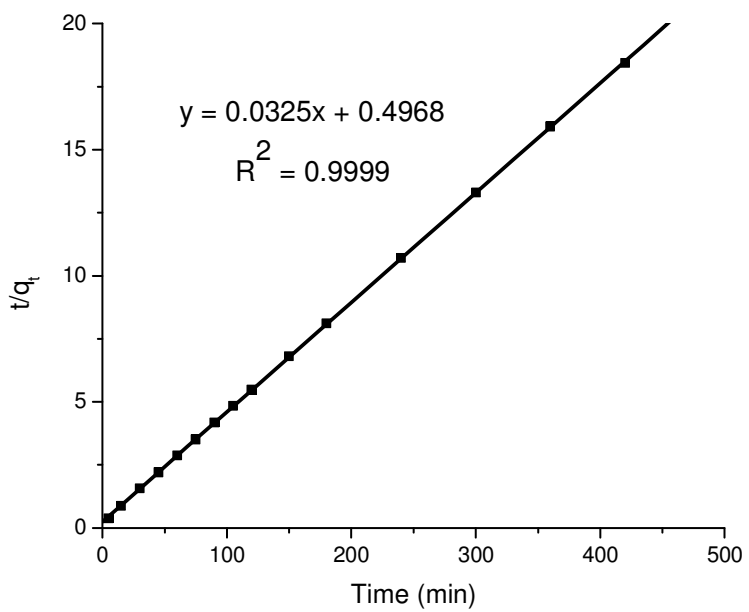

Figure 6. Average pseudo-second order plot of fluoride adsorption kinetics on adsorbents each with the same initial load $(\mathrm{pH}=7.01-7.18$, contact time, $10 \mathrm{~h})$.

The results were also analyzed in terms of intraparticle diffusion model to investigate whether the intraparticle diffusion was the rate controlling step in adsorption of fluoride on to nano-AlOOH. The model used here was proposed by Weber and Morris [35]. The linear form of the equation is represented by:

$q_{t}=K_{d} t^{1 / 2}$

where, $\mathrm{q}_{\mathrm{t}}$ is the amount adsorbed $\left(\mathrm{mg} \mathrm{g}^{-1}\right)$ at time $\mathrm{t}$ and $\mathrm{K}_{\mathrm{d}}\left(\mathrm{mg} \mathrm{g}^{-1} \mathrm{~min}^{1 / 2}\right)$ is the intraparticle diffusion rate constant.

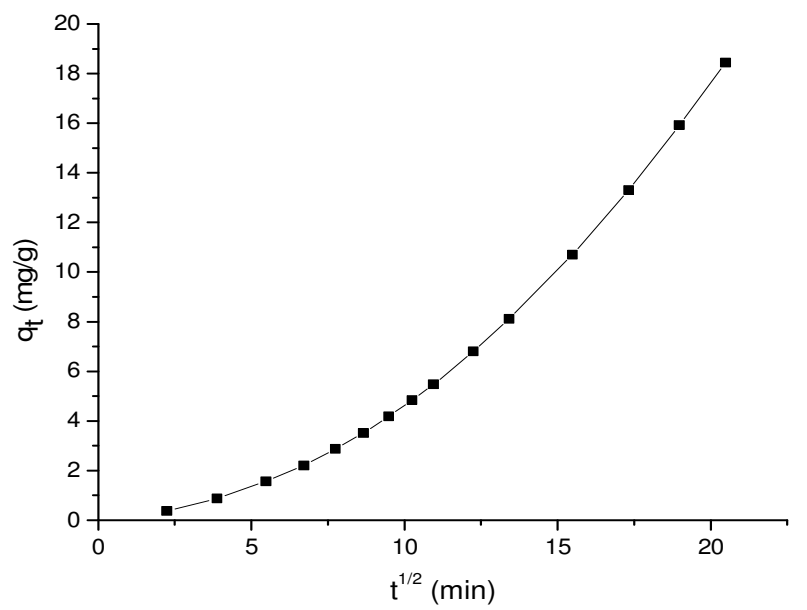

Figure 7. Weber and Morris intraparticle diffusion plot for the removal of fluoride by nano$\mathrm{AlOOH}$.

If a plot of $\mathrm{q}_{\mathrm{t}}$ versus $\mathrm{t}^{1 / 2}$ gives a straight line that pass through the origin, then it suggests that the intraparticle diffusion contributes predominantly in the rate-determining step [36]. However,

Bull. Chem. Soc. Ethiop. 2014, 28(2) 
if the data exhibit multi-linear plots, then it is anticipated that other mechanisms are also involved along with intraparticle diffusion. Thus, as can be seen from Figure 7 different regions can be identified which indicates different mechanisms.

The instant initial linear and subsequent curved portion reflects the external surface adsorption and film or boundary layer diffusion effect [36]. The last sharp linear portion of the plot attribute to the intraparticle diffusion effect and the equilibrium uptake. Based on the result it may be concluded that the adsorption mechanism of fluoride ion by nano-AlOOH from aqueous solution is complex process and the intraparticle diffusion was not the only ratecontrolling step. Since, the linear portion of the curve does not pass the origin and this result is consistent with the work of other studies [37] and [38].

\section{Adsorption mechanism}

To further investigate the interaction between fluoride ion and nano- $\mathrm{AlOOH}$, the change in $\mathrm{pH}$ during the adsorption process was studied. As shown in Table 2, the $\mathrm{pH}$ of the solution after the sorption reaction increased for a solution with initial $\mathrm{pH}$ below 8 . However, for initial $\mathrm{pH}$ of solution greater than or equal to 8 the final $\mathrm{pH}$ became decreased after the sorption process. Thus, adsorption of fluoride at initial $\mathrm{pH}$ below 8 might be takes place by ion exchange reaction, i.e. due to the replacement of hydroxide ion $\left(\mathrm{OH}^{-}\right)$by fluoride ion $(\mathrm{F})$ as shown in the equation below and this is evident from the rise of $\mathrm{pH}$.

$\mathrm{AlOOH}+\mathrm{F}^{-} \mathrm{AlO}-\mathrm{F}+\mathrm{OH}^{-}$

The result is also in agreement with the adsorption mechanism proposed by D-R isotherm model. The adsorption processes have adsorption energy value of $13.15 \mathrm{~kJ} \mathrm{~mol}^{-1}$ for $\mathrm{F}^{-}$ions on to nano-AlOOH. If the magnitude of free energy of adsorption is between 8 and $16 \mathrm{~kJ} \mathrm{~mol}^{-1}$, the adsorption process corresponds to chemical ion-exchange type, and the value of $\mathrm{E}<8 \mathrm{~kJ} \mathrm{~mol}^{-1}$ represents a physical adsorption [39] and [40]. The energy value for fluoride ions sorption on to nano- $\mathrm{AlOOH}$ indicates that the sorption process is predominantly chemical ion-exchange in nature.

Table 2. Change in $\mathrm{pH}$ after adsorption process. $\left(\mathrm{C}_{\mathrm{o}}=20 \mathrm{mg} \mathrm{L}^{-1}\right.$, contact time $=1 \mathrm{~h}$, and dose $\left.=1.6 \mathrm{~g} \mathrm{~L}^{-1}\right)$.

\begin{tabular}{|c|c|c|}
\hline Initial $\mathrm{pH}$ of the solution & Final $\mathrm{pH}$ of the solution & $\Delta \mathrm{pH}$ \\
\hline 3 & 4.55 & +1.55 \\
\hline 5 & 6.27 & +1.27 \\
\hline 6 & 6.86 & +0.86 \\
\hline 7 & 7.32 & +0.32 \\
\hline 8 & 6.59 & -1.41 \\
\hline 9 & 7.38 & -1.62 \\
\hline 10 & 7.69 & -2.31 \\
\hline
\end{tabular}

On the other hand adsorption of fluoride at an initial $\mathrm{pH} \geq 8$, the surface slowly acquires negative charges which would repel fluoride ions and hence the fluoride removal by electrostatic attraction is ruled out in alkaline medium. Thus, the sorption might be take place by physical sorption process. Since, nano-AlOOH has a $\mathrm{pH}_{\mathrm{pzc}}$ of 7.8 , which means that the surface of the adsorbent presents a net negative charge when $\mathrm{pH} \geq 7.8$ [28]. 


\section{CONCLUSION}

Nano-AlOOH has considerable potential for the removal of excess fluoride from aqueous solution. For a given initial fluoride concentration, the removal efficiency of the adsorbent increased with increasing adsorbent dose. Adsorption of fluoride is very rapid in the first $30 \mathrm{~min}$ and then increases slowly to reach pseudo-equilibrium. Initial concentration of fluoride found to affect the fluoride removal efficiency of the adsorbent. High fluoride removal occurred between $\mathrm{pH} 6$ to 8, and appreciable amount of fluoride was removed around $\mathrm{pH} 7$. The equilibrium data were tested to fit Freundlich, Langmuir, D-R and Temkin isotherm models in order to understand the mechanism of fluoride adsorption at the surface of $\mathrm{AlOOH}$. Therefore, the Langmuir isotherm model corresponded to better with the experimental data and the maximum adsorption capacities; $\mathrm{q}_{\mathrm{m}}$ of the adsorbent was $62.50 \mathrm{mg} \mathrm{g}^{-1}$. The D-R model gave adsorption energy $13.15 \mathrm{~kJ} \mathrm{~mol}^{-1}$, which indicates the fluoride removal by nano-AlOOH is chemisorption process. Adsorption kinetics followed and well described by a pseudo-second order model. Mechanism of the adsorption process on the basis of change in $\mathrm{pH}$ after adsorption process and the free energy value from D-R model was an ion exchange mechanism. Intraparticle diffusion was not the rate controlling step during the adsorption process. Comparison of adsorption capacity and contact time required for maximum adsorption of fluoride (equilibrium time) with some other sorbents, nano-AlOOH has shown better adsorption potential and performance.

\section{ACKNOWLEDGMENTS}

This research was supported by the National Science Foundation (NSF) and USAID PEER grant No. AID-OAA-A-11-00012 to Feleke Zewge. The authors would like to thank the Swiss Federal Institute of Aquatic Science and Technology (Eawag) for their technical support during characterization of the adsorbent.

\section{REFERENCES}

1. Pietrelli, L. Ann. Chim. 2005, 95, 303.

2. Symonds, R.B.; Rose, W.I.; Reed, M.H. Nature 1988, 334, 415.

3. WHO, World Health Organization Guidelines for Drinking-Water Quality, First Addendum to Third Edition, World Health Organization: Geneva, Switzerland; 2006.

4. CRC, Cooperative Research Center, CRC for water quality and treatment investigation of defluoridation options for rural and remote communities, Research Report No 41; ISBN 18766166679; Australia; 2008.

5. Jamode, A.V.; Spakal, V.S.; Jamode, V.S. J. Ind. Inst. Sci. 2004, 84, 163.

6. Tekle-haimanot, R.; Fekadu, A.; Bushura, B. Trop. Geog. Med. 1987, 39, 209.

7. Nemade, P.D.; Rao, A.V.; Alappat, B.J. Water Sci. Technol. 2002, 2, 311.

8. Kloos, H.; Tekle-haimanot, R. Trop. Med. Int. Health 1999, 4, 355.

9. Reimann, C.; Bjorvatn, K.; Frengstad, B.; Zeneb, M.; Redda, T.; Siewers, U. Sci. Total Environ. 2003, 311, 65.

10. Dissanayake, C.B. Int. J. Environ. Stud. 1991, 19, 195.

11. WHO, World Health Organization Guidelines for Drinking Water Quality. 3rd ed., World Health Organization: Geneva, Switzerland; 2004; p 375.

12. Shrivastava, B.K.; Vani, A. Asian J. Exp. Sci. 2009, 23, 269.

13. Nawlakhe, W.G.; Kulkarni, D.N.; Pathak, B.N.; Bulusu, K.R. Ind. J. Environ. Health 1975, 17, 26.

14. Min, B.R.; Gill, A.L.; Gill, W.N. Desalination 1984, 49, 89. 
15. Tahaikt, M.; Habbani, R.; Eli, H.; Ait, A.; Achary, I.; Amazor, Z.; Taky, M.; Alami, A.; Boughriba, A.; Hafsi, M.; Elmidaoui, A. Desalination 2007, 212, 46.

16. Nalan, K.; Ozgur, A.; Saba, S.; Umran, Y.; Mithat, Y. J. Hazard. Mater. 2008, 153, 107.

17. Sanjeev, S.; Rohini, J.; Naveen, S.M.; Mahesh, S. Electrocoagulation using DC current for removal of fluoride from ground water, Proceedings of International Conference on Energy and Environment; 2009; p 2070.

18. Ghorai, S.; Pant, K.K. Sep. Purif. Technol. 2005, 42, 265.

19. Fawell, J.; Bailey, K.; Chilton, J.; Dahi, E.; Fewtrell, L.; Magara, Y. Fluoride in Drinking Water, WHO and IWA Publishing: London; 2006.

20. Shemelis, B.; Zewge, F.; Chandravanshi, B.S. Bull. Chem. Soc. Ethiop. 2006, 20, 17.

21. Dahi, E. The state of art of small community defluoridation of drinking water. $3^{\text {rd }}$ International Workshop on Fluorosis Prevention and Defluoridation of Water; Chiang, Mai and Thailand; 2000; p 137.

22. Bardsen, A.; Bjorvant, K. Fluoride sorption in fired clay, in Proceeding of the First International Workshop on Fluorosis and Defluoridation of Water; Tanzania; 1997; 46.

23. Moges, G.; Zewge, F.; Scoher, M. J. Afr. Ear. Sci. 1996, 21, 479.

24. Zevenbergen, C.; Van Reeuvijk, L.P.; Louws, R.J.; Schiling, R.D. Sci. Total. Environ. 1996, $188,225$.

25. Negussie, W.; Zewge, F.; Chandravanshi, B.S. J. Hazard. Mater. 2007, 147, 954.

26. Sundaram, C.S.; Viswanathan, N.; Meenakshi, S. J. Hazard. Mater. 2008, 155, 206.

27. Parida, K.M.; Amaresh, C.P.; Das, J.; Naruparaj, S. J. Mater. Chem. Phys. 2009, 113, 244.

28. Wang, S.G.; Yue, M.; Yijing, S.; Wen, X. J. Chem. Technol. Biotechnol. 2009, 84, 1043.

29. Bailey, P.L. Analysis with Ion-selective Electrodes, 3rd ed., Heidon: London; 1980; p 196.

30. Wefers, K.; Misra, C. Oxides and hydroxides of aluminium, Alcoa Technical Paper No.19; 1987.

31. Scherrer, P. Math.-Phys. Kl. 1918, 2, 98.

32. Kim, Y.; Kim, C.; Choi, I.; Rengraj, S.; Yi, J. Environ. Sci. Technol. 2004, 38, 924.

33. Sujana, M.G.; Thakur, R.S.; Rao, S.B. J. Colloid Interf. Sci. 1998, 206, 94.

34. Sarkar, M.; Banerjee, A.; Pramanick, P.P.; Sarkar, A.R. J. Colloid Interf. Sci. 2006, 302, 432.

35. Weber, W.J.; Morris, J.C. J. Sanit. Eng. Div. 1963, 89, 31.

36. Ghorai, S.; Pant, K.K. Sep. Puri. Technol. 2005, 42, 265.

37. Sundaram, C.S.; Viswanathan, N.; Meenakishi, S. J. Hazard. Mater. 2009, 172, 147.

38. Meenakshi, S.; Sundaram, C.S.; Sukumar, R. J. Hazard. Mater. 2008, 153, 164.

39. Rieman, W.; Walton, H. Ion exchange in analytical chemistry, in International Series of Monographs in Analytical Chemistry, Pergamon: Oxford; 1970; p 38.

40. Kiran, I.; Akar, T.; Ozcan, A.S.; Ozcan, A.; Tunali, S. J. Biochem. Eng. 2006, 31, 199. 